\title{
Determinant of Solid-Waste Management in Debre Birhan Town
}

\author{
Adimias Wendimagegn \\ Department of Statistics, College of Natural and Computational Science, Debre Berhan University, Debre Berhan, Ethiopia \\ Email address: \\ adimaswend@gmail.com \\ To cite this article: \\ Adimias Wendimagegn. Determinant of Solid-Waste Management in Debre Birhan Town. American Journal of Theoretical and Applied \\ Statistics. Vol. 8, No. 1, 2019, pp. 26-30. doi: 10.11648/j.ajtas.20190801.14
}

Received: December 14, 2018; Accepted: February 27, 2019; Published: March 27, 2019

\begin{abstract}
Most of the developed countries recognized that solid waste management is very crucial for survival (economically) in addition to secure the safety of environment and human health. However, the developing countries like Ethiopia, let alone use its economic benefits, because of various reasons they are dumping of wastes in unauthorized sites, which easily expose to harsh hazards, like environmental pollution and health problem. Hence, the overall objective of the study is to describe and analyze the household solid waste management current situation and examine the influence of demographics, socio-cultural and institutional factors on the factor influencing of solid waste management at household level in the town. The data used in this study for the analysis were obtained from statistical survey by self-administered questioner and direct personal interview method with reference to a total of 1166 households which were selected through simple random sampling. Logistic regression model was used to identify factors that influencing solid waste management at household level in the study area. Though all households have temporary storage in their home, they did not store wastes separately based on its nature. The empirical analyses, using the logistic regression model, shows that, household head educational level, household's willingness to pay for waste collector, household's awareness on solid waste management service are the major determinants of household solid waste management in the study area. Moreover, the qualitative analyses, using the interview, show that manpower, budget, and facilities such as container, adequate vehicles, waste gown, and gloves are the other major factors of solid waste management at household level in debre Birhan town.
\end{abstract}

Keywords: Household Solid Waste Management, Logistic Regression, Debre Birhan

\section{Introduction}

\section{Background of the Study}

The rapid urbanization that has been taking place during the $20^{\text {th }}$ century virtually transformed the world into communities of cities and towns facing similar challenges on environmental issues in which most of them have to be addressed at international level. Solid waste management became a worldwide agenda at United Nation conference on environment and development in Rio de janeiro in 1992 with a great emphasis on reducing waste and maximizing environmentally sound waste reuse and recycling at first step in waste management $[1,2]$.

In recent years, urbanization is increasing in most developing countries including Ethiopia. Due to this, the low and middle income countries are really suffering from imbalance between the amount of waste generation and the capacity which need to properly manage their wastes. Imbalance is severely affecting the health condition of the society and the general environmental soundness [4, 5].

Moreover, the primary objective of solid waste management activity is to make the environment sound and safe in human health via disposed of wastes in a wellorganized manner. However, through process the stakeholders of the management system, especially in the developed nations, did not stop on disposed of waste in open dump or landfill only rather they tried to convert the trash/solid wastes/ to cash and make strong their economy in addition to environmental aspect. It is very much worthy to directly quote the finding of Smith: "For most industrialized nations today, solid waste management is a multibillion dollar business which is also crucial to survival. Garbage collection agencies remove tons of garbage yearly and sort it for recycling or ultimate disposal" [6]. 
In addition to the above benefit of well managed solid wastes, it surely is important to produce methane gas for the purpose of electric power generation [3].

However, let alone getting the above stated benefits, Solid waste management (SWM) is one of the critical challenges of developing countries including Ethiopia because of the social, economic and environmental implications once not properly managed. Only $30-50 \%$ of the waste generated in developing countries is collected and managed properly. The rest is either burned or left to decompose in open space or dumped in unregulated landfills, which is damaging the environment. Developed countries are able to manage the various types of waste to an acceptable level, contrary to developing nations like Ethiopia which are still struggling to deal with the problem of proper management of solid wastes. With the current rate of urbanization municipal solid waste collection, transportation and disposal have been a major problem of municipalities in most of the Ethiopian cities. Collection of municipal solid waste in most of the cities is difficult and complex because the generation of residential, commercial and industrial waste is a diffuse process that takes place in every house, every building and every commercial and industrial facility as well as in the streets, parks and even in the vacant areas available within the community. In addition to this hilly terrain of many cities, lack of manpower, equipment and financial constraints are factors which aggravate the problem [7-10].

In Ethiopia, alike developing countries, the increase of solid waste generation is resulted from rapid urbanization and population booming. The amount of solid waste in Debre Berhan town and other fast growing areas in the country has been increasing over time, largely attributed to rapid population growth rate. From the total solid waste released by the population in the city, about $50-60 \%$ was collected and the rest was unattended. Recently the municipality has increased its coverage to about $85 \%[7,11]$.

Moreover, household solid wastes in Debre Birhan town are observed on the road, burning inside the village and disposed in sewerage. This clearly indicated that, Debre Birhan town population rate and the waste generation rate per household is increasing. But the solid waste management, particularly at household level, is not managed in a wellorganized manner. Proper budget is not allocated for municipal waste management. Municipal solid waste management (MSWM) is an integral part of good local governance and one of the most visible urban services influencing local perception of governance. Debre Birhan has also problems that prevent the municipality/ responsible body from doing its task for environmental sound with economic efficiency. This study aims to evaluate the solid waste management system in Debre Birhan town, by identifying factor influencing solid waste management $[11,12]$.

Improper handling and on site disposal of solid wastes poses a serious problem, which contribute to high morbidity and mortality rate in the town. In MSWM an important starting point is the knowledge of basic data such as the generation rate, characteristics, formal and informal operations in place including producers' behavior. Such information is vital for planning, setting targets and evaluating such targets [12].

Investigation of the existing management practices and factors that constrain these practices is believed to be important in order to gain understanding of the challenges and issues involved in municipal solid waste management. Thus, this research work would try to investigate the key demographic and socio-economic factors such as the relationship between education levels of the household, household size, income, institutional involvement, distance of community waste bin; infrastructure and solid waste management are the focal point of this study.

The general objective of this study is to assess the factors influencing solid-waste management in Debre Birhan Town.

This study would help to generate data and gather information on the municipal solid waste management in Debre Birhan town. Thus the study was hoped to provide some information to policy makers, donors, and environmental protection practitioners who are interest to assist financial, training and legal provision which in turn minimize the constraints of MSWM.

\section{Literature Review}

There has been considerable the number of researches conducted; focused on factors that affect waste management. Waste is often found as a liquid or solid form. Solid waste is any type of wastes which is hard or not a water-like or liquid form; for example, used plastic bags, broken bags, leftover food or foods remains and the like. It is a by-product of human activities that tends to increase with the rate of urbanization, changing patterns of consumption and the improvement of living standards [13, 14].

The human activities which take place in this world create waste. The wastes could be both solid and liquid types; and the way they are going to be handled, stored, and disposed can expose the environment and public health to risks. If solid waste is properly used, it can be a valuable resource, but if it is not effectively managed, it can result in serious adverse impacts on environment and public health. Solid waste management is therefore a critical component within urban sanitation and it is also one of the most important and resource intensive services provided by municipalities $[15$, $16]$.

Solid waste management is becoming a major public health and environmental concern in urban areas of Ethiopia. In Ethiopia, like developing countries, increase of solid waste generation is resulted from rapid urbanization and population booming and the average solid waste generation rate is about $0.221 \mathrm{~kg}$ per person per day and it is also estimated that only $2 \%$ of the population received solid waste collection services. One of the poorest environmental performances in Ethiopia pertains to the management of all types of waste and the country lack any disposal or destruction facility, sanitary landfills and incineration. For instance, in Debre Birhan hazardous solid wastes totally untreated, may be put into the 
city's municipal dump when properly disposed of, or remain dealt with in the general environment and the situation in Debre Birhan is now being Repeated in the fast developing urban centers throughout the country $[16,17]$.

\section{Methodology}

\section{Logistic Regression Model}

Logistic regression model is preferable when the dependent variable is qualitative (categorical) in nature. It describes the relationship between a categorical response variable and any set of explanatory variables.

\section{Binary logistic regression}

Binary logistic regressions were used to perform logistic regression on a binary response variable. A binary variable has only two possible values, such as presence or absence of a particular event. Models with one or more predictors; we fitted using an iterative-reweighed least squares algorithm to obtain maximum likelihood estimates of the parameters. Binary logistic regression has also been used to classify observations into one of two categories, and it may give fewer classification errors than discriminates analysis for some cases. The binary logistic regression function is defined as:

$$
\Pi(\mathrm{X})=\frac{e^{\beta 0+\beta 1 \times 1+\beta 2 \times 2+\beta 3 \times 3+\cdots+\beta p \times p}}{1+e^{\beta 0+\beta 1 \times 1+\beta \times 2+\beta 3 \times 3 \ldots \beta p \times p}}
$$

Where, $\beta_{o}=$ the constant of the equation $\beta_{i}=$ the coefficient of the, $\mathrm{i}^{\text {th }}$ predictor.

\section{Result of Statistical Analysis and Discussion}

Binary logistic regression is applied to assess the relationship between overall perception of persons which is dichotomized response variable (Yes/No) and independent variables. SPSS version 16 is used to perform binary logistic regression by making positive perception as reference category.

Table 1. Omnibus test of model coefficient of influencing solid waste management.

\begin{tabular}{lllll}
\hline & & Chi-square & Df & Sig. \\
\hline \multirow{3}{*}{ Step 1 } & Step & 74.264 & 8 & .000 \\
& Block & 74.264 & 8 & .000 \\
& Model & 74.264 & 8 & .000 \\
\hline
\end{tabular}

The null hypothesis of Omnibus test of model coefficient states that information about the independent variables does not allow us to make better prediction of dependent variable. Therefore we went to be state, the chi-squared value is significant because the value of $\mathrm{p}=0.000$ is less than values of $\alpha=0.05$. We have sufficient evidence to reject $\mathrm{H}_{0}$, and conclude that there is association between independent variable and influencing solid waste management.

Table 2. Hosmer and Lemeshow Test for the influencing solid waste management.

\begin{tabular}{llll}
\hline Step & chi-square & Df & s.g \\
\hline 1 & 6.966 & 8 & 0.540 \\
\hline
\end{tabular}

The Hosmer and Lemeshow Test is a measure of fit which evaluates the goodness of fit between predicted and observed probabilities in classifying the response variable. The hypothesis is;

$\mathrm{H}_{0}$ : the model is good fit $\mathrm{v}_{\mathrm{s}}$

$\mathrm{H}_{1}$ : the model is not good fit

Since the Hosmer-Lemeshow goodness of fit test P-value is 0.540 which is greater than 0.05 , we do not reject the null hypothesis that is the predicted and observed values are closed. Therefore, at the final stage result of the HosmerLemeshow statistics lead to the non-rejection of the null hypothesis saying the model fits the data which agrees with the previous likelihood ratio test.

Table 3. Variables in the Equation.

\begin{tabular}{|c|c|c|c|c|c|c|c|c|c|}
\hline & & \multirow{2}{*}{ B } & \multirow{2}{*}{ S.E. } & \multirow{2}{*}{ Wald } & \multirow{2}{*}{ Df } & \multirow{2}{*}{ Sig. } & \multirow{2}{*}{$\operatorname{Exp}(B)$} & \multicolumn{2}{|c|}{$95.0 \%$ C.I. for $\operatorname{EXP}(B)$} \\
\hline & & & & & & & & Lower & Upper \\
\hline \multirow{9}{*}{ Step $1^{\mathrm{a}}$} & education(primary and above) & .862 & .643 & 1.800 & 1 & .180 & 2.368 & .672 & 8.343 \\
\hline & Stay & -.041 & .027 & 2.354 & 1 & .125 & .960 & .910 & 1.012 \\
\hline & family(above 5) & -1.423 & .597 & 5.684 & 1 & .017 & .241 & .075 & .776 \\
\hline & pay(no) & -.939 & .538 & 3.041 & 1 & .081 & .391 & .136 & 1.123 \\
\hline & Awareness (no) & -1.669 & .568 & 8.625 & 1 & .003 & .188 & .062 & .574 \\
\hline & Service & & & 7.339 & 2 & .025 & & & \\
\hline & service(enough access) & 1.212 & .814 & 2.215 & 1 & .137 & 3.360 & .681 & 16.578 \\
\hline & policy(yes) & -1.810 & .535 & 11.463 & 1 & .001 & .164 & .057 & .467 \\
\hline & Constant & 1.413 & .884 & 2.558 & 1 & .110 & 4.109 & & \\
\hline
\end{tabular}

\section{Interpretation of odds ratio}

The odds ratios of currently being solid waste manage for primary education level are greater than one about 2 (OR $=2.368$ ) time the odds uneducated level of currently being solid waste manage by taking the other variable are constant. The coefficient of year of stay is negative indicating that when the year of stay is decrease by one year then to dispose solid waste manage is decrease by $4 \%(\mathrm{OR}=0.96)$ given that the effects of other variable are constant. And the odds of currently being solid waste manage of family size (above 5) are less than one implying that about $75.9 \%$ ( $\mathrm{OR}=0.241$ ) as compared the reference by taking the other variable are 
constant.

The odd of currently being solid waste manage for the not willing to pay for waste collectors is less than about $60.9 \%(\mathrm{OR}=0.391)$ as compared with the reference by taking the other variable are constant. The odds of currently no awareness about solid waste manage technique is less than one implying about $81.2 \%(\mathrm{OR}=0.188)$ as compared with communities who have awareness about solid waste manage technique by taking the other variable are constant. Similarly the odds of currently being solid waste manage to not enough access for waste storage are greater than one about 9 $(\mathrm{OR}=9.016)$ times the odds of currently being solid waste manage for no evidence about the waste storage around their village by taking the other variable are constant. Enough access is greater than one about $3(\mathrm{OR}=3.360)$ as compared to the reference of none at all by taking the other variable are constant. Finally, the odds ratios of currently being solid waste manage for implementation of government policy is less than one about $83.6 \%(\mathrm{OR}=0.164)$ as compared with doesn't implementation government policy by taking the other variable are constant.

\section{Conclusion}

Solid waste management is being a serious agenda in the world since it is a major cause for environmental pollution and human health risks this study also indicated that Debre Birhan town dispose solid waste management practice is very weak in terms of status, spatial coverage and solid waste management facility. This study intended to identify the most important socio-demographic characteristics of solid waste management. It implies that, the type and rate of household solid waste production are varied depending on the living condition of each household. The town municipality did not assign solid waste container in any parts of the town; rather, they orient the household to store their wastes and handover to the private waste collectors or municipal vehicle when it tours in their village.

Significance testing for the logistic coefficients using Wald test and likelihood ratio show that family size, awareness, access of private collector's serves, and government policy implementation are significant factors.

To assess the fitness of the model the maximum likelihood ratio test and Hosmer and Lemeshow test are used. As we can see the fitted binary logistic regression model is expectedly determined the socio-cultural, demography factor on dispose solid waste management in Debre Birhan town.

\section{References}

[1] Smith, 2010. What is Solid Waste Management? Retrieved from http://www.wise greek.com/ what-is-solid-wastemanagment.htm web page Accessed, August 26/ 08/2013.

[2] UNEP, 1996. International Source Book on Environmentally Sound Technologies for Municipal Solid Waste Management. UNEP Technical Publication 6, Nov. 1996. Retrieved from (http://www.unep.or.jp/ietc/estdir/pub/msw/).
Web page Accessed, August18, 2013.

[3] Rouse, J. (2008) planning for sustainable municipal solid waste management: Practical Action; the Schumacher Centre for Technology and Development Bourton-on-Dunsmore Rugby, Warwickshire, CV23 9QZ. United Kingdom.

[4] Solomon, A. (2006) Solid Waste Management: A Case Study of Household Solid Waste Management in Arada SubCity, Addis Ababa. A Master's Thesis presented to the school of graduate studies of Addis Ababa University. Addis Ababa, Ethiopia.

[5] SMSWG (2008) Global waste challenges: Situation in Developing Countries; Department of water and sanitation in developing countries at EAWAG, conducted under the support of Swiss Federal Institute of Aquatic Science and Technology. Available at: http://www.novaquatis.eawag.ch/organisation/abteilungen/sa ndec/schwerpunkte/swm/index EN (Accessed date: 10 December 2010).

[6] Smith S. E. (2003) what is solid waste management. Available at: http://www.wisegeek.com/what- is-solidwaste-management.htm. (Accessed date: 02 Jan 2011).

[7] Dawit Walelign and Alebel Bayrau, 2003. Improvement of solid waste management in Addis Ababa, a participatory Approach (Draft), Addis Ababa, Ethiopia.

[8] Beyene, A., Legesse, W., Triest, L. \&Kloos, H. (2009), "Urban impact on ecological integrity of nearby rivers in developing countries: the Borkena River in highland Ethiopia", Environmental Monitoring and Assessment, 153(1-4), pp- 461-476.

[9] Mulu, T. \&Legesse, W. (2005), "Analysis of the type and amount of Solid Waste generated and adopted Disposal Methods by the Residents of Bonga City", Ethiopian Journal of Health Sciences, 15 (2), 157-165.

[10] Sharma, H. R., Abebe, T., Admassu, M., Teshaye, T., Aseffa, T., \& Emana, M. (2011), "Municipal Solid Waste Management and Community Awareness and Involvement in Management and Practice: an overview and a case study from Gondar town of Ethiopia", Int. J. Environment and Waste Management, 7(3/4), 294-304.

[11] AACGSBPDA, 2005. Current status of solid waste management of Administration of Addis Ababa.

[12] Rushbrook, Philip, Push, and Michael. 1999. Solid Waste Landfills in Middle and Lower Income Countries: A Technical Guide to Planning, Design and Operation. Word Bank, Washington. D. C.

[13] ILO (2007) Start Your Waste Recycling Business: A Technical Step-By-Step-Guide of How to Start a Community-Based Waste Recycling Business. Norfolk Rd, Mt Pleasant Arundel Office Park PO Box 210 Harare, Zimbabwe.

[14] ENPHO (2008) Solid waste management in Nepal. 110/25 Adarsa Marga-1, Thapagaon, New Baneshwor GPO Box: 4102, Kathmandu, Nepal. Available at www.enpho.org. (Accessed date: 25 January 2011).

[15] Zhu, D. Asnani, U. P. Zurbrügg, C. Anapolsky, s. and Mani, s. (2008) Improving municipal solid waste management in India: A sourcebook for policy makers and practitioners. Available at http://www.infibeam.com (Accessed date: 18 may 2011). 
[16] Zebenay Kassa, 2010. The Challenges of Solid Waste Management in Urban Areas, the Case of Debremarkos Town, Addis Ababa University, Ethiopia.
[17] UNCED (2002). Ethiopian Country Profile. World Submit on Sustainable Development. From August 26 to sep 4, 2002, Johannesburg, South Africa. 